\title{
THE PSYCHOLOGICAL IMPACTS OF INTERNET PORNOGRAPHY ADDICTION ON ADOLESCENTS
}

\author{
Rr. Setyawati ${ }^{1 *}$; Nurul Hartini²; ${ }^{2}$ Suryanto $^{3}$ \\ ${ }^{1,2,3}$ Faculty of Psychology, Universitas Airlangga \\ Jl. Airlangga No. 4-6, Surabaya, Jawa Timur 60115, Indonesia \\ 'rorosetyawati@yahoo.co.id; ${ }^{2}$ nurul.hartini@psikologi.unair.ac.id; ${ }^{3}$ suryanto@psikologi.unair.ac.id
}

Received: 03 ${ }^{\text {rd }}$ September 2020/ Revised: $19^{\text {th }}$ September 2020/ Accepted: $26^{\text {th }}$ October 2020

How to Cite: Setyawati, R., Hartini, N., \& Suryanto. (2020). The psychological impacts of internet pornography addiction on adolescents. Humaniora, 11(3), 235-244. https://doi.org/ 10.21512/humaniora.v11i3.6682

\begin{abstract}
The research aimed to reveal the impacts by adolescents who experienced internet addiction with pornographic content. It applied a qualitative approach, namely an instrumental case study. Participants were 18-25 years old, there were six adolescents who were obtained based on the initial screening, namely self-reporting through a pornography internet addiction questionnaire. The data were collected by in-depth interviews, observation, and documentation. Thematic analysis with NVivo 12 data management was used as the data analysis technique. The results show that adolescents experience changes in cognition and affection for sexual stimulation caused by the internet with pornographic content. The impact of cognition is shown from their obsessive-compulsive thoughts on sexual content. They always have the desire to see those photos or video over again, which lead them to sleep disorders due to visualizing scenes of sexual intercourse. The impact of affection can be seen from their desire to act in sexual activity, their being so passionate and pleased after seeing pornographic content, and their expectation to feel such immense affection. Furthermore, they might find difficulty in establishing interpersonal relationships with other people and tend to withdraw themselves from the social environment.
\end{abstract}

Keywords: psychological impacts, internet pornography addiction, adolescent addiction

\section{INTRODUCTION}

The rapid advancement of internet has emerged many terms related to internet addiction with pornographic content. Several research results indicate a number of terms used, which are internet pornography use(Grubbsetal.,2017; Short etal., 2016); internet pornography addiction (Love et al., 2015); compulsive pornography use (Kohut \& Štulhofer, 2018b; De Sousa, 2019); excessive pornography use (Blaszczynski, 2016) excessive internet pornography use (Essig, 2015); problematic pornography use (Gola et al., 2016, 2017); problematic internet pornography use (Chen \& Jiang, 2020); compulsive pornography consumption (Noor, Rosser \& Erickson, 2014; Rosser, Noor \& Iantaffi, 2014); compulsive use of sexually explicit internet material (Doornwaard et al., 2016); 2016); internet pornography use disorder (Antons \& Brand, 2018; Pekal et al., 2018). Therefore, the research uses the term internet addiction with pornographic content after reviewing research results in several scientific journals.

In fact, research on internet addiction with pornographic content still becomes a topic of debate for its existence by scientists and health practitioners. There is no specific diagnostic for addiction to internet pornography since it has not been included in the Diagnostic and Statistical Manual of Mental Disorders/ DSM-5 (American Psychiatric Association, 2017) or the latest version of the International Classification of Diseases-11/ICD 11, which complicates this problem. Not to mention that there is still a debate whether internet pornography addiction is an extension of sexual addiction with the internet as a medium, which causes negative consequences in life (Griffiths, 2012) or is involving other types of addiction (Young, 2009).

Addiction, in the Cambridge Advanced Learner's Dictionary and Thesaurus, is describes as the need or 
strong desire to do or to have something, or a very strong liking for something. There are many experts who define internet addiction, however, the reference of experts in defining internet addiction is basically almost the same, especially definition of behavioral addiction (Caplan, 2002). Caplan et al. (2009) sees technology addiction as part of behavioral addiction; and internet addiction as one of the major components of addiction (i.e., significance, mood modification, tolerance, withdrawal, conflict, and relapse). Griffiths et al. (2016) defines internet addiction as addictive behavior which involves interactions between humans and machines without the use of drugs.

Young $(1998,2008)$ defines addiction as a habit forced to engage in certain activities or make use of substances, not by bearing adverse consequences on the physical, social, spiritual, mental and financial health of individuals. Instead of overcoming life's obstacles, dealing with everyday stressors, and/or dealing with past or present trauma, addicts respond maladaptively by turning to pseudo-coping mechanisms. Behavioral addiction is pre-occupation with the behavior, diminished ability to control the behavior, tolerance, withdrawal, and adverse psychosocial consequences (Grant et al., 2010).

Internet pornography is defined as the use of the internet for sexual activities, such as viewing pornographic images, chatting about sex, exchanging pictures or videos about sex which is sometimes followed by masturbation (Cooper et al., 2004). The definition of pornography in Law Number 44 of 2008 concerning pornography is sexuality material made by humans in the form of images, sketches, illustrations, photos, writings, sounds, videos, animations, cartoons, conversations, gestures, or messages, and others through various forms of communication media and public performances containing obscenity or sexual exploitation that violates the norms of decency in society.

Internet pornography is a merely attractive medium due to the nature of Triple A, namely accessibility, affordability, and anonymity (Cooper et al., 2003). Accessibility refers to the fact that the internet provides millions of pornographic sites and chat rooms allowing opportunities for pornographic activities online. Affordability, namely accessing pornographic sites provided by the internet, does not need to be expensive. Meanwhile, anonymity means that individuals do not need to be afraid of being recognized by others. Teens can hide their identity when accessing sensitive information about sexuality due to privacy and anonymity (de Alarcón et al., 2019; Shim \& Paul, 2014). The characteristics of internet pornography as mentioned above provide opportunities for adolescents to fulfill their curiosity about sexuality without any restrictions that are appropriate for their developmental age. Exposure to pornographic content may have a risk to develop compulsive behavior and addiction (Grubbs et al., 2019; Wetterneck et al., 2012).

Young (1998) states that addiction to internet pornography can be seen in a person who compulsively searches porn sites or cybersex. Internet addiction behavior on pornographic objects based on internet addiction criteria can be seen from several compatible indicators (Griffiths et al., 2016), including immersion, excessive time, and lack of control. Immersion here is feeling immersed in or preoccupied with the internet with pornographic content. Excessive time means that individuals always need additional time to achieve a certain level of satisfaction when using the internet to access pornographic content. The absence of control means that individuals are no longer able to control, reduce, or stop using the internet to access pornographic content.

Addiction to internet pornography can be seen from several criteria according to the opinions of several figures. Internet porn addiction can be determined based on hours of use per week (Cooper et al., 1998) while others are based on reported increased usage patterns (Young, 2008). Pornography addiction relies on participatory evaluation of the behaviors and emotional experiences associated with use. This subjective evaluation is manifested in: the number of attempts made to access pornographic internet; lack of control over the use of pornographic content; and emotional distress associated with its use (Grubbs et al., 2015).

Therefore, based on the previous research, the researchers come up with the definition of addiction to internet pornography. It is an online compulsive behavior that dominates life in a maladaptive manner using the internet for excessive sexual content to raise sexual arousal with a loss of ability to control one self's behavior towards sexual contents made by humans through various forms of communication media and public performances, which contain obscenity or sexual exploitation violating the norms of decency in society. The research, with theoretical contribution, aims to reveal the impact experienced by adolescents who experience internet addiction with pornographic contents.

\section{METHODS}

The qualitative approach is chosen to carry out an in-depth study on a phenomenon of internet pornography addiction by delivering clear and in-depth elaboration from the data. The research describes the psychological impact on adolescents who are merely addicted to pornographic contents on the internet. Creswell et al. (2007) states that a case study is a research strategy in which researchers carefully investigate a program, event, activity, process, or group of individuals, whereas Stake (2013) states that a case-study research is to reveal the peculiarities or uniqueness of the characteristics in the cases. Researchers chose to use instrumental case study research to examine and provide in-depth understanding or explain a generalization process. Through the cases, the researchers intend to show that 
there is something unique that can be learned, which is different from the explanations obtained from other objects.

Participants should be about 18-25 years old because based on the results of some studies this age range is included in the category of late adolescence towards adulthood. This period is characterized by exploration in the fields of sexuality and identity, as well as increased participation in risky behavior (Arnett, 2014). Six adolescents become the participants of this research. This number is obtained based on the initial screening, namely self-reporting through internet addiction questionnaires with pornography content and psychological examinations.

According to Yin (2018) data are collected from documents, archival records, interviews, observations and physical devices. Therefore, data collection procedures are conducted in-depth interviews, observation and documentation.

According to Bogdan and Biklen (1992) an interview is a purposeful conversation, usually between two people directed by a person with the intention of obtaining information. Interviews are conducted with the principle of dialogue, discussion to build understanding and meaning in solving problems. Concurrent interviews can be carried out with participant observation, document analysis, or other techniques.

The research applies participatory observation, in which the role of the researcher is as an actor and as an observer (Willig, 2019). This participating observation is to observe adolescent behavior by indirect observation through secondary participants, which are the participants' family and friends.

Documentation techniques are used to obtain supporting data that cannot be done by interviewing or observation techniques. The documentation turns out to be participant notes and psychologist examinations.

Boyatzis (1998), in Alhojailan (2012) states that qualitative research data analysis is to find the meaning of natural truth believed by the researcher and understood by readers of the research report. The data are analyzed using thematic analysis, which is a process that allows the translation of qualitative symptoms/information into qualitative data as needed by the researcher. Researchers use data management software NVivo 12 Plus to organize data since researchers play a major role in the research and analysis process.

The six general steps for carrying out thematic analysis are guidelines, which should not be used as prescriptive, linear, and inflexible rules when analyzing data (Braun \& Clarke, 2006). These steps should be used in conjunction with the research question and available data. The first step is familiarizing the data by making a transcript of the interview results into verbatim, which are then read to obtain the initial ideas. The second step is generating the initial code, in which the researcher makes coding systematically based on interesting facts from data and collects relevant data for each code. The third stage is looking for themes, in which the researchers compile the code into potential themes and collects all relevant data with each potential theme.

The fourth step is reviewing the theme by checking whether the theme is functioning in relation to the results of reducing data to code (Level 1) and the entire data set (Level 2) and producing thematic 'maps' from the analysis. The fifth step is defining and naming the themes, in which the researcher carries out a continuous analysis to make the specifications of each theme and the overall verbatim analysis as suggested before, and then produces a clear definition and name for each theme. The sixth step is compiling the analysis report by selecting clear and interesting sample extracts. The final analysis of the selected extracts is linked with research questions and literature to produce a scientific report.

The research is considered trustworthy if it has credibility, transferability, and dependability. To fulfill the credibility, the test is intended to obtain more indepth data about research participants. Testing the credibility data from qualitative research results, among others, is carried out by extending observations with 3 meetings with participants, by increasing persistence in research, triangulation, and having discussions with peers which involves fellow psychologists and academics to discuss research topics.

Transferability is external validity related to the degree of agreement or application of research results to the population where the sample is taken. The researcher should provide a detailed, clear, systematic, and reliable description. If the readers get a clear and coherent delivery, it can provide an overview of the research results which can be applied, thus the report meets the transferability standard.

Finally, the researchers conduct a dependability test by conducting an audit of the entire research process. The researchers provides a progress report at each stage of the research process, namely: (1) the research problem; (2) the research focus; (3) the research field; (4) the data source; (5) data analysis; (6) data validity; and (7) the conclusions.

\section{RESULTS AND DISCUSSIONS}

This section elaborates the results on the experiences of adolescents who are merely addicted to pornography internet. The results include two themes, namely the experience of accessing the internet with pornographic content and the impacts of accessing the internet with pornographic content.

The responses from experience of accessing pornographic content are made into three categories: (1) the first-time for participants being exposed to pornography; (2) the duration of viewing pornography on the internet; and (3) ways to access pornographic contents. Table 1 presents the experience of accessing the internet with pornographic content. 
Table 1 Experience of Accessing the Internet with Pornographic Content

\begin{tabular}{ll}
\hline First time accessing & Start to access the internet \\
pornographic content & with pornographic content \\
on the internet & when they were 11-13 years \\
& old. \\
The duration of Consumption
\end{tabular} The duration of Consumption r of
the internet with pornography is getting pornographic content longer, and pornographic videos have various lengths of time.

The way to access The participants use the internet with cellphones online, borrow pornographic content cellphones from friends and are taught by friends how to access pornographic content internet, and use their parents' cellphones.

Participants access through various website.

Participants using social media applications have a dimension of accessing the pornographic content group from social media.

Participants can tell exactly at what age they accessed internet for pornography. Participants experience exposure to pornographic content when they were 11-13 years old, which is conveyed by all participants as seen in the following transcripts.

$\leq$ Files $\backslash$ Interview

Transcript || VERBATIM PARTISIPAN JF $>-\S$ 10 references coded "I did it for the first time when I was in the sixth grade of Elementary School..." Reference 1 - 0,22\% Coverage

\section{$<$ Files $\backslash$ Interview}

Transcript||VERBATIM DISERTASI VN $>-\S$ 3 references coded $[13,01 \%$ Coverage] "The first time I saw sexual content or pornographic videos was when I was in the second grade of junior high school."

Regarding duration, consumption of pornographic content on the internet has become routine so that the duration of consuming is getting longer, not to mention that pornographic videos have various lengths of time. Accessing the internet with pornographic content became a routine habit of the participants. They have been doing it for six years due to the easy access to various porn sites. The transcript of interview results is:

\section{$<$ Files $\backslash$ Interview}

Transcript $\mid \backslash T U L I S A N$ PARTISIPAN JF $>-\S 1$ reference coded $[2,48 \%$ Coverage $]$ "Gradually, the blue videos that I saw were getting longer in duration and having more various in style. The first blue videos I saw were only four to five minutes long. When I was in the end of my junior high school, the video I downloaded from the 'waptrick' site was fifteen minutes long."

The third category is the way to access pornographic content. It is found that the participants use their own cellphones, borrow cellphones from friends as well as parents' cellphones to go online. They use a mobile phone application to share sexual content and use Bluetooth to obtain pornographic videos offline. Participants use an application from the Playstore to download pornographic videos, use additional applications such as UC Browser, Share It, VPN, YouTube, and Twitter. These data were taken based on the statement from participants.

\section{$<$ Files $\backslash$ Interview \\ Transcript $\mid \backslash$ VERBATIM DISERTASI IB $>-\S 8$ references coded [2,98\% Coverage]" yes, I had downloaded it first so that I don't need to be online before. Reference 1 - 0,38\% Coverage... well, I have to access it again when I have enough credit. Reference 2 - 0,17\% Coverage... I just need to fidn the video by typing the keywords of it. Reference 3 - 0,23\% Coverage..."}

Furthermore, participants have access through the website by entering to www.waptrick.com, selecting videos they desired and downloading them, as seen in the transcript of the interview.

\section{$<$ Files $\backslash$ Interview \\ Transcript $\backslash \backslash$ TULISAN PARTISIPAN JF $>-\S 1$ reference coded $[2,48 \%$ Coverage $]$ "...I have downloaded from Watprick sites. Watprick has been the suppier of porn videos I can count on. When I opened Waptrick, I found a menu of the videos which one of them was Video xxxx. When the menu is typed, there will appear many kinds of video."}

Participants using social media applications have a dimension of accessing the pornographic content group from social media, such as Facebook and WhatsApp. They use accounts to enter groups to get links that contain thousands of sexual content, choose a good front and a good panel, view Facebook posts that particularly discuss pornography, listen to conversations on Facebook, stalk on 18+ accounts to get information on pornographic content links, as seen in the following transcripts.

$\leq$ Files $\backslash$ Interview $\quad$ Transcript ||$V E R B A T I M$ DA $>-\S 3$ references coded [2,19\% Coverage] "After stalking in account $18+$, I got a comment. Directly we continued stalking. Hahahahaha..." Reference 1 - 0,57\% Coverage 
$<$ Files $\backslash$ Interview

Transcript $\mid \backslash$ VERBATIM DISERTASI IB $>-\S 8$ references coded $[2,98 \%$ Coverage] "...well, I have to search the good ones, the good panels which have good fore-parts." Reference 5 $0,44 \%$ Coverage

Psychological impacts of internet pornography addiction are divided into three categories: (1) impact on cognition; (2) effect on affection; and (3) effect on behavior. Table 2 shows psychological impacts of Internet pornography addiction.

Table 2 Psychological Impacts of Internet Pornography Addiction

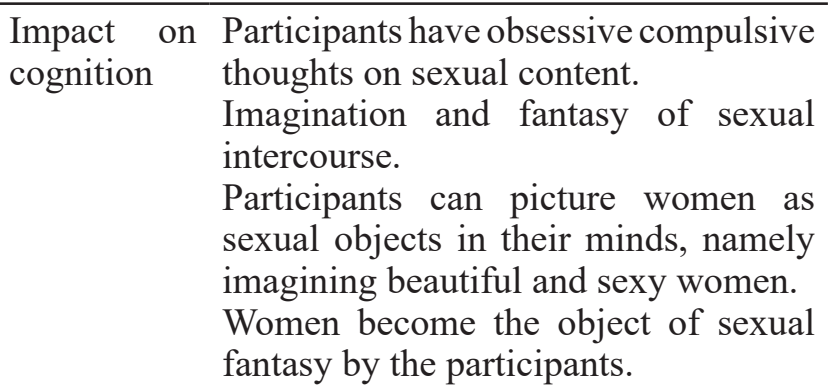

Effect on Participants have sexual passion, there affection are such feelings of lust and excitement of the urge to engage in sexual activity after seeing pornographic content.

Participants have sexual satisfaction after sexual activity.

Effect on Participants have difficulty in making behavior friends and initiating communication, Participants like being alone, thus finding difficulty to get along with others and in group situations,

Having difficulties in getting along with friends in organizations.

Sexual contents occurs to have impacts on cognition. Participants have obsessive compulsive thoughts on sexual content, namely remembering pornographic content that has been watched since they first consumed it. They cannot help to think, focus, expect to watch, and imagine the sexual content that has been watched. They find it hard to focus on doing things since they have trouble sleeping due to having fantasies about sexual intercourse scenes. The statement can be seen in the interview transcript.

\section{$<$ Files $\backslash$ Interview}

Transcript $\backslash \backslash$ VERBATIM DA $>-\S 4$ references coded $[1,52 \%$ Coverage $]$...Reference 1 $0,29 \%$ Coverage

"Well, let me think...Reference 2 - 0,23\%

Coverage... sometimes it comes to my mind....Reference 3 - 0,40\% Coverage... yes, sometimes it haunts me... then, I can't focus to do anything.." Reference 4 - 0,60\% Coverage "...yes, I feel distressed, it seems something missing so I can't sleep well thinking it over and over again..."

Participants can have imaginary dimensions of sexual intercourse scenes from videos they have seen. The appearance of strange sexual content images eventually disturbs them when having casual conversation with boyfriends or girls.

\section{$\leq$ Files $\backslash \backslash$ Interview \\ Transcript $\backslash \mid V E R B A T I M ~ S A P>-\S 3$ references coded $[2,44 \%$ Coverage] "...Reference 1 - $2,06 \%$ Coverage... When I was dating, I only wanted to talk with her. However, I always think something odd. When I was with other woman, I also thought the same. This disturbed me much. 2 - 0,24\% Coverage...yes sure, it haunts me..." Reference 3 - 0,14\% Coverage "...yes, the film."}

Participants are able to describe it in their minds, women as sexual objects, namely imagining beautiful and sexy women. Sometimes, they used their partners for sexual intercourse scenes in their minds or fantasize the women as in videos and in sexual scenes and fantasize about hiring prostitutes to have sex with. These are based on following statement quotes:

\section{Files \Interview}

Transcript $\backslash \backslash P A R T I S I P A N T ' S$ NOTE JF $>-\S$ 6 references coded $[4,87 \%$ Coverage] "... She looks like the Japanese porn actress named Maria Ozawa.....Her face is nearly the same, almost 90\% with the girl whom I had touched just now........afterwards, I often glanced at the girl, then I photograph her face while thinking in my evil thoughts to take her to a quiet place to act what I think..." Reference 1 - 1,20\% Coverage

\section{$\leq$ Files $\backslash \backslash$ Interview \\ Transcript $\backslash \backslash$ VERBATIM DISERTASI IB $>-\S 6$ references coded [2,75\% Coverage] "I imagine to book one... yeah I really want to book a streetwalker, then I take her home or to hotel or wherever.." Reference 3 - 0,64\% Coverage}

In addition, women become the object of sexual fantasy of the participants since they memorize the women in the photos or videos. In their imagination, they choose the desired artist, teacher and friend to have sex with. It is stated in the interview script.

$<$ Files $\backslash \backslash$ InterviewTranscript $\backslash \backslash$ TULISAN PARTISIPAN JF $>$ - $\S 6$ references coded [4,87\% Coverage $]$ "...As usual, I photographed her face while thinking to bring her reflection to a quiet place. Then, in that shadow I saw that the teacher was so beautiful in my evil thoughts. It looks so real and I can only gasp at the room. 
What makes worse is that to find out that the teacher will teach biology subjects in my class for a year. At that time when I turned that beautiful teacher into my regular imagination in that hot slime-filled action." Reference 4 $1,54 \%$ Coverage.

Participants will photograph the teacher's face in their mind and take the image to a quiet place. In his imagination, the teacher's figure looks beautiful and real that he gasped for air in the room. This becomes his habits of hot slime-filled action. In fact, rape appears to be a sexual fantasy, namely imagining raping a woman. This is based on the following statement:

\section{$\leq$ Files $\backslash$ Interview \\ Transcript $\mid$ VERBATIM DISERTASI IB $>-\S$ 6 references coded [2,75\% Coverage] "Yes there is, when I'm watching, I really want to do something. For example, when there was a girl passing by me, I was thinking what I should to her ... I was thinking to grab and rape her like that, if a girl is sexy or beautiful, but then, I was questioning why I should do that action." Reference 1 - 1,01\% Coverage}

Psychologically, internet pornography addiction has effects on affection. Participants have sexual passion, such as feelings of lust and excitement of the urge to engage in sexual activity after seeing pornographic content. The participants want to do the same acts and intimate relationships in the video to vent lust and even always want to feel higher arousal. This fact was based on the following statement:

\section{$<$ Files $\backslash$ Interview \\ Transcript $\mid$ VERBATIM DISERTASI VN $>-\S$ 1 reference coded [1,25\% Coverage] "I'm very excited, I want to masturbate..." Reference 1 - $1,25 \%$ Coverage "... I used to be very excited, because there were a lot of videos exalting me much...."}

Sexual satisfaction occurs after sexual activity. Adolescent sometimes experience a feeling of pleasure and relief, convenience, excitement and joy and satisfaction. Pornographic content is a medium for sexual stimulation which has a passionate dimension when watching kissing scenes, feeling more lustful and attracted to women, wishing to have a sexually intimate relationship with their significant others.

\section{$<$ Files $\backslash$ Interview}

Transcript $\backslash \backslash$ TULISAN PARTISIPAN JF $>-\S$ 6 references coded $[4,87 \%$ Coverage $]$ " ... The shows teach me how to gain intimacy."

\section{$<$ Files $\backslash$ Interview}

Transcript IVERBATIM DISERTASI IB $>$ - § 28 references coded $[7,30 \%$ Coverage] “...I became relieved..." Reference $13-0,07 \%$ Coverage "...for example.....my P...It's relieved.." Reference 14 - 0,16\% Coverage “... It satisfied that... mmm.... satisfying my sexual appetite..." Reference 4 - 0,27\% Coverage

Finally, pornographic contents on the internet is considered to impact viewers' behavior. They tend to find it difficult making friends, initiating communication, and getting along with others in groups or organizations since they would prefer being alone.

\section{$<$ Files \Interview}

Transcript || VERBATIM PARTISIPAN JF $>-\S$ 14 references coded [1,68\% Coverage] "well talking about the way.., sometimes I ask Rahma about it, she told me to be together often. Yes, I am often together with others. However, when I am with others, sometimes I don't always get along with them right away, Mom. I also feel difficult to make friends after I watch the content" Reference 4 - 0,13\% Coverage “... I enjoy being alone, I prefer to be alone, for example when doing my own assignments or even doing group assignments, I prefer doing them by myself." Reference $9-0,16 \%$ Coverage

Since being familiar with the internet, pornography maniacs have spent a lot of time in their room and tend to cover up this habit from anyone around them.

\section{$<$ Files $\backslash$ Interview}

Transcript $\mid \backslash$ VERBATIM DISERTASI VN $>$ - $\S 5$ references coded $[7,83 \%$ Coverage] "... I stayed in the room all the time while I was watching it in the site". Reference $1-1,36 \%$ Coverage "... I never tell anyone, because that is my privacy ..."

The participants manage to withdraw themselves in social situations, such as turning away from people and avoiding interactions, which can be seen from the interview transcript.

\section{$\leq$ Files $\backslash$ Interview \\ Transcript || VERBATIM DA $>-\S 7$ references coded $[6,50 \%$ Coverage] “...Reference 1 - $0,30 \%$ Coverage...yeah I stay away from people..." Reference 2 - 1,45\% Coverage “... just like keeping distance, so I don't interact too often with people, because it's impossible for other people to understand me about why and for what, so that's all. I stay calm more..." Reference 3 - 0,99\% Coverage "...When I am in the crowds where I know the people, it's still normal, but when I am in the crowds where I don't know the people, that's a bit uncomfortable..." Reference 4 - 0,54\% Coverage}

Pornography addicts have tendency to feel disturbed when they have visiting relatives to their houses since they are not as free to view sexual 
contents as when they are alone. They tend to stay in their room until parents tell them to come out and greet the guests. Not to mention that they tend to be more sensitive as they feel not much comfortable in having conversations with others.

\begin{abstract}
$\leq$ Files $\backslash \backslash$ Interview
Transcript $\backslash \backslash$ VERBATIM SAP $>-\S 7$ references coded $[5,03 \%$ Coverage $]$... Reference 1 - 0,88\% Coverage "...yes, I just feel uncomfortable when someone else comes home, just like that..." Reference 2 - 0,26\% Coverage “... yes, it bothers me to watch it..." Reference 3 - 0,28\% Coverage "... all I do is only staying away..." Reference 4 - 1,60\% Coverage "... when a guest or someone come to my house, I just keep silent or I ask my mother to meet them," Reference $5-1,47 \%$ Coverage "...no, it depends on the situation. It is annoying to see many people in my house, I don't like this. It is so disturbing... I become so sensitive with them" Reference 6 $0,41 \%$ Coverage "... meeting other people and talking with them in such a way..." Reference 7 - 0,11\% Coverage "...it is not comfortable."
\end{abstract}

Participants are uncomfortable being in a crowd with strangers. It occurs that they feel dizzy and embarrassed, in some ways, to be surrounded by people. They tend to be reluctant to make small talk when meeting people, thus they would rather be lonely yet busy with their cellphone.

\section{$<$ Files $\backslash$ Interview \\ $\underline{\text { Transcript } \backslash \backslash \text { VERBATIM DA }>-\S 7 \text { references }}$ coded [6,50\% Coverage] “...yeah, I just feel shy, such uncomfortable feeling. I am often busy with my HP." Reference 5 - 0,81\% Coverage "Yeah, I only answer accordingly. I don't feel comfortable in the crowds. I feel so dizzy to see them all." Reference 6 - 0,84\% Coverage “...I am dizzy in crowds. I prefer quiet place. I don't like to be involved in their complicated small talks." Reference 7 - 1,57\% Coverage “...Well, when I feel okay with others I don't know well in the crowds, I can control myself. But, when I don't have good mood and I find it annoying, I just want to go back very soon."}

Based on the interview transcripts, it occurs pornographic content in the era of modern technology is different from the previous time. Simple pictures and videos start to become meaningless because internet pornography is replaced as an unlimited reality and transforms into a new force. The power of internet pornography is far more powerful as it produces an endless drive of addiction that can never be satisfied. The first-time participants begin to be exposed to pornographic content is at the time of puberty. This shows that the sexual information on the internet are potentially consumed by early teenagers. The participants recall that they were in elementary school and junior high school when they first accessed pornography content in the internet. Participants initially just felt curious to know things related to sexual content. On the other hand, participants have entered the range of puberty in which sexual development begins to appear. When participants accessed pornography for the first time, they were at the stage where they have not had any understanding on their biological and hormonal changes. Viewing pornographic content at such early stage of puberty is a shocking, lurid and fearful experience. The individuals might experience a loss of control over their habits which eventually lead to addiction.

Addiction to internet pornography is based on the symptoms of internet addiction as stated by Young (1998). The research findings show that the participants experience the immersion, which is the condition when the participants feel carried away by watching the pornographic scenes so that they tend to repeat the search and download the videos to watch them all over again. Tolerance means that the longer experience leads to longer duration and more video variations. Salience is a participant fantasizing by imagining a woman who is considered attractive to be the object of masturbation. Mood modification is a state when participants feel an unprecedented desire to kiss a woman even in public. Participants feel increasingly unsatisfied due to years of masturbation. Craving for pornographic contents has become something that is very much desired by participants. They consider porn videos to have become part of their body. Withdrawal symptoms is a condition when the participants regret that they have made consumption of pornographic videos as a part of their daily activities. However, the participant participants find it difficult to remove pornographic videos from their minds.

Furthermore, participants experience intrapersonal and interpersonal conflicts. For instance they find difficulties in socializing since they are much more comfortable being alone in the room. Not to mention that they might also be insecure to confess their feelings for the opposite sex. Relapse is a condition when participants re-access and download pornographic content after trying to hold back, but failing.

Exposure to pornographic content on the internet leads to pornography addiction, especially in adolescents who are still experiencing puberty, in which they have not reached the stage of adolescents' social psychological maturity. This finding is in line with research by Joyal, Cossette and Lapierre (2015). Second, affection impact consist of sexual arousal and sexual satisfaction are: (1) desire and pleasure from seeing pornographic content; (2) the urge to perform sex scenes to achieve higher arousal. Another psychological effect is a significant relationship between the intensity or frequency of accessing pornography and feelings of loneliness, including major depression (Kohut \& Štulhofer, 2018a). Individuals who access online pornography tend to experience clinical problems, namely depressive symptoms than individuals who seek 
pornography offline or different means. Addiction to internet pornography also affects the emotional life of adolescents so they are prone to nightmares, feelings of shame, guilt, anxiety and confusion as well as selfesteem, feelings of dissatisfaction with one's body and sexual anxiety. This finding is in line with research by (Doornwaard et al., 2016).

Behulu et al. (2019) show that adolescents receive information through pornographic content that emphasizes physical appearance and masters sexual intercourse techniques. Pornography will have an impact on sexual attitudes, beliefs, behavior and sexual aggression, self-concept, body image, social development, and brain function and physical development of adolescents (George et al., 2019). It is further explained by Jonsson et al. (2014) who have conducted a research on 3.503 youths in Sweden. They mention that the experience of intentional online sexual exposure is related to internet behavior, social background and psycho-social health including parent-child relationships. They prove a significant association between intentional sexual exposure online and a number of different forms of online harassment. Respondents have significantly worse psycho-social health and problematic relationships with parents. Moreover, pornography addiction in adolescents lead to an attitude of approving prostitution, supporting sexual relations without love and affection, and underestimating love (van Oosten \& Vandenbosch, 2020). Gradually, pornographic display can have a negative influence on changes in attitude or behavior from the results of the learning process through imitation. At the next stage, pornography addicts tend to experience a process of increasing need which will eventually lead to deviant behavior among adolescents.

These findings show that the pornographic content by adolescents contains complex messages about gender, power, sexual health, body, pleasure, consent, performance, sexuality and sex. Repeated exposure to pornography results in findings that there is a decrease in the sensitivity of adolescents to the material being viewed and it leads to a distorted view of "acceptable" behavior in relationships. Duffy et al (2016) furtherly explain that cognitive distortions are related to the use of pornographic content. Pornographic display will gradually have a negative influence on changes in attitudes or behavior from the results of the learning process through imitation will eventually trigger deviant behavior among adolescents.

\section{CONCLUSIONS}

Internet pornographic content have huge impacts for adolescents, especially on their cognitive and affective changes in their sexual stimulation. There are many behaviors that the impacts of cognition can be seen from: (1) obsessive compulsive thoughts on sexual contents; (2) recalling pornographic contents when consuming it for the first time; (3) thinking about sexual contents that have been watched; (4) focusing on the sexual content; (5) starting to be addicted to them by imagining sexual content that has not been viewed; (6) having lack of focus on doing things and (7) having difficulty in sleeping due to fantasies about sexual intercourse scenes.

The impacts of affection can be found from their emergence of passion and pleasure from watching pornographic content, the urge to perform scenes and intimate relationships in the video to vent lust and feel such immense affection. Furthermore, internet addiction with pornography has an impact on social behavior, which these adolescents may find difficulty in establishing interpersonal relationships with other people and tend to withdraw themselves from the social environment.

The research represents a limited number of participants so that it cannot be used to generalize to other individuals who are addicted to the internet with pornographic content. In addition, enforcement of internet addiction with pornographic content considers that there has not been a standard to determine the severity and lightness of the pornography addiction. Not to mention that internet addiction with pornographic content based on self-reporting questionnaires is not a psychologist's diagnosis.

Internet addiction with pornography content is a problem that requires handling from several parties, namely the government, parents, and the community. Teenagers need to get internet pornography literacy to fortify themselves from exposure to the internet with pornographic contents that are increasingly circulating without limits. Further research is suggested to examine related variables such as self-efficacy, selfconcept and social relations of adolescents who experience pornography internet addiction.

\section{ACKNOWLEDGMENTS}

On this occasion, the researcher would like to thank and appreciate much to Mrs. Dr. Nurul Hartini, M. Kes, Psychologist, as the Academic Advisor who has given me her best guidance, supports, suggestions as well as directions in her very busy times. I am especially indebted to Mr. Prof. Dr. Suryanto the chairman of my committee. As a teacher and mentor, he has taught more than I could ever give him credit for here. This work would not have been possible without the financial support of the LPDP (Indonesia Endowment Fund for Education) which has provided the fund for doctoral studies.

\section{REFERENCES}

Alhojailan, M. I. (2012). Thematic analysis: A critical review of its process and evaluation. West East Journal of Social Sciences, 1(1), 39-47.

American Psychiatric Association. (2017). DSM-5 Update. Diagnostic and Statistical Manual of Mental 
Disorder (5 $5^{\text {th }}$ Ed.). Retrieved from https://www. psychiatry.org/psychiatrists/practice/dsm.

Antons, S., \& Brand, M. (2018). Trait and state impulsivity in males with tendency towards Internet-pornographyuse disorder. Addictive Behaviors, 79, 171-177. https://doi.org/10.1016/j.addbeh.2017.12.029.

Arnett, J. J. (2014). Presidential address: The emergence of emerging adulthood: A personal history. Emerging Adulthood, 2(3), 155-162. https://doi. org/10.1177/2167696814541096.

Behulu, G. K., Anteneh, K. T. and Aynalem, G. L. (2019). Premarital sexual intercourse and associated factors among adolescent students in Debre-Markos town secondary and preparatory schools, north west Ethiopia, 2017. BMC Research Notes, 12(1), 4-9. https://doi.org/10.1186/s13104-019-4132-4.

Blaszczynski, A. (2016). Excessive Pornography use: Empirically-enhanced treatment interventions. Australian Clinical Psychologist, 2(1), 1-9.

Bogdan, B., \& Biklen, S. K. (1992). Quality Research for Education: An Introduction to Theory and Methods. Boston: Allyn \& Bacon.

Braun, V., \& Clarke, V. (2006). Using thematic analysis in psychology. Qualitative Research in Psychology, 3(2), 77-101. https://doi. org/10.1191/1478088706qp063oa.

Caplan, S. E. (2002). Problematic Internet use and psychosocial well-being: Development of a theorybased cognitive-behavioral measurement instrument. Computers in Human Behavior, 18(5), 553-575. https://doi.org/10.1016/S0747-5632(02)00004-3.

Caplan, S., Williams, D., \& Yee, N. (2009). Problematic Internet use and psychosocial well-being among MMO players. Computers in Human Behavior, 25(6), 1312-1319. https://doi.org/10.1016/j. chb.2009.06.006.

Chen, L., \& Jiang, X. (2020). The assessment of problematic internet pornography use: A comparison of three scales with mixed methods. International Journal of Environmental Research and Public Health, 17(2), 488-502. https://doi.org/10.3390/ijerph17020488.

Cooper, A., Delmonico, D. L., Griffin-Shelley, E., \& Mathy, R. M. (2004). Online sexual activity: An examination of potentially problematic behaviors. Sexual Addiction and Compulsivity, 11(3), 129-143. https://doi.org/10.1080/10720160490882642.

Cooper, A., Månsson, S. A., Daneback, K., Tikkanen, R., \& Ross, M. W. (2003). Predicting the future of Internet sex: Online sexual activities in Sweden. Sexual and Relationship Therapy, 18(3), 277-291. https://doi.or $\mathrm{g} / 10.1080 / 1468199031000153919$.

Cooper, M. L., Shapiro, C. M., \& Powers, A. M. (1998). Motivations for sex and risky sexual behavior among adolescents and young adults: A functional perspective. Journal of Personality and Social Psychology, 75(6), 1528-1558. https://doi. org/10.1037//0022-3514.75.6.1528.

Creswell, J. W., Hanson, W. E., Clark Plano, V. L., \& Morales, A. (2007). Qualitative research designs: Selection and implementation. The Counseling Psychologist, 35(2), 236-264. https://doi. org/10.1177/0011000006287390.

de Alarcón, R., de la Iglesia, J., Casado, N., \& Montejo, A. (2019). Online porn addiction: What we know and what we don't - A systematic review. Journal of Clinical Medicine, 8(1), 91-111. https://doi. org/10.3390/jcm8010091.

De Sousa, A. (2019). Compulsive pornography use in late life: A case report. Journal of Psychosexual Health, 1(3-4), 275-276. https://doi. org/10.1177/2631831819890766.

Doornwaard, S. M., van den Eijnden, R. J. J. M., Baams, L., Vanwesenbeeck, I., \& ter Bogt, T. F. M. (2016). Lower psychological well-being and excessive sexual interest predict symptoms of compulsive use of sexually explicit internet material among adolescent boys. Journal of Youth and Adolescence, 45(1), 73-84. https://doi.org/10.1007/s10964-0150326-9.

Duffy, A., Dawson, D. L., \& das Nair, R. (2016). Pornography addiction in adults: A systematic review of definitions and reported impact. Journal of Sexual Medicine, 13(5), 760-777. https://doi. org/10.1016/j.jsxm.2016.03.002.

Essig, T. (2015). The gains and losses of screen relations: Aclinical approach to simulation entrapment and simulation avoidance in a case of excessive internet pornography use. Contemporary Psychoanalysis, 51(4), 680-703. https://doi.org/10.1080/00107530.2 015.1023669 .

George, M., Maheshwari, S., Chandran, S., \& Rao, T. S. S. (2019). Psychosocial aspects of pornography. Journal of Psychosexual Health, 1(1), 44-47. https:// doi.org/10.1177/2631831818821535.

Gola, M., Lewczuk, K., \& Skorko, M. (2016). What matters: Quantity or quality of pornography use? Psychological and behavioral factors of seeking treatment for problematic pornography use. Journal of Sexual Medicine, 13(5), 815-824. https://doi. org/10.1016/j.jsxm.2016.02.169.

Gola, M., Wordecha, M., Sescousse, G., Lew-Starowicz, M., Kossowski, B., Wypych, M., Makeig, S., Potenza, M. N., \& Marchewka, A. (2017). Can pornography be addictive? An fMRI study of men seeking treatment for problematic pornography use. Neuropsychopharmacology, 42(10), 2021-2031. https://doi.org/10.1038/npp.2017.78.

Grant, J. E., Potenza, M. N., Weinstein, A., \& Gorelick, D. A. (2010). Introduction to behavioral addictions. American Journal of Drug and Alcohol Abuse, 36(5), 233-241. https://doi.org/10.3109/00952990.2 010.491884

Griffiths, M. D. (2012). Internet sex addiction: A review of empirical research. Addiction Research and Theory, 20(2), 111-124. https://doi.org/10.3109/16066359.2 011.588351 .

Griffiths, M. D., Kuss, D. J., Billieux, J., \& Pontes, H. M. (2016). The evolution of internet addiction: A global perspective. Addictive Behaviors, 53, 193-195. https://doi.org/10.1016/j.addbeh.2015.11.001.

Grubbs, J. B., Exline, J. J., Pargament, K. I., Volk, F., \& Lindberg, M. J. (2017). Internet pornography 
use, perceived addiction, and religious/spiritual struggles. Archives of Sexual Behavior, 46(6), 17331745. https://doi.org/10.1007/s10508-016-0772-9.

Grubbs, J. B., Perry, S. L., Wilt, J. A., \& Reid, R. C. (2019). Pornography problems due to moral incongruence: An integrative model with a systematic review and meta-analysis. Archives of Sexual Behavior, 48(2), 397-415. https://doi.org/10.1007/s10508-0181248-x.

Grubbs, J. B., Stauner, N., Exline, J. J., Pargament, K. I., \& Lindberg, M. J. (2015). Perceived addiction to Internet pornography and psychological distress: Examining relationships concurrently and over time. Psychology of Addictive Behaviors, 29(4), 10561067. https://doi.org/10.1037/adb0000114.

Jonsson, L. S., Priebe, G., Bladh, M., \& Svedin, C. G. (2014). Voluntary sexual exposure online among Swedish youth - Social background, Internet behavior and psychosocial health. Computers in Human Behavior, 30, 181-190. https://doi.org/10.1016/j. chb.2013.08.005.

Joyal, C. C., Cossette, A., \& Lapierre, V. (2015). What exactly is an unusual sexual fantasy? Journal of Sexual Medicine, 12(2), 328-340. https://doi. org/10.1111/jsm.12734.

Kohut, T., \& Štulhofer, A. (2018a). Is pornography use a risk for adolescent wellbeing? An examination of temporal relationships in two independent panel samples. PLoS ONE, 13(8), 1-20. https://doi. org/10.1371/journal.pone.0202048.

Kohut, T., \& Štulhofer, A. (2018b). The role of religiosity in adolescents' compulsive pornography use: A longitudinal assessment. Journal of Sex and Marital Therapy, 44(8), 759-775. https://doi.org/10.1080/00 92623X.2018.1466012.

Love, T., Laier, C., Brand, M., Hatch, L., \& Hajela, R. (2015). Neuroscience of internet pornography addiction: A review and update. Behavioral Sciences, 5(3), 388433. https://doi.org/10.3390/bs5030388

Noor, S. W., Rosser, B. R. S., \& Erickson, D. J. (2014). A brief scale to measure problematic sexually explicit media consumption: Psychometric properties of the Compulsive Pornography Consumption (CPC) scale among men who have sex with men. Sexual Addiction and Compulsivity, 21(3), 240-261. https:// doi.org/10.1080/10720162.2014.938849.

Pekal, J., Laier, C., Snagowski, J., Stark, R., \& Brand, M. (2018). Tendencies toward internet-pornography-use disorder: Differences in men and women regarding attentional biases to pornographic stimuli. Journal of Behavioral Addictions, 7(3), 574-583. https://doi. org/10.1556/2006.7.2018.70.
Rosser, B. R. S., Noor, S. W. B., \& Iantaffi, A. (2014). Normal, problematic, and compulsive consumption of sexually explicit media: Clinical findings using the Compulsive Pornography Consumption (CPC) scale among men who have sex with men. Sexual Addiction and Compulsivity, 21(4), 276-304. https:// doi.org/10.1080/10720162.2014.959145.

Shim, J. W., \& Paul, B. M. (2014). The role of anonymity in the effects of inadvertent exposure to online pornography among young adult males. Social Behavior and Personality, 42(5), 823-834. https:// doi.org/10.2224/sbp.2014.42.5.823.

Short, M. B., Wetterneck, C. T., Bistricky, S. L., Shutter, T., \& Chase, T. E. (2016). Clinicians' beliefs, observations, and treatment effectiveness regarding clients' sexual addiction and Internet pornography use. Community Mental Health Journal, 52(8), 1070-1081. https://doi.org/10.1007/s10597-0160034-2.

Stake, R. E. (2013). Qualitative research and case study. Silpakorn Educational Research Journal, 3(1-2), 7-13.

van Oosten, J. M. F., \& Vandenbosch, L. (2020). Predicting the willingness to engage in non-consensual forwarding of sexts: The role of pornography and instrumental notions of sex. Archives of Sexual Behavior, 49(4), 1121-1132. https://doi.org/10.1007/ s10508-019-01580-2.

Wetterneck, C. T., Burgess, A. J., Short, M. B., Smith, A. H., \& Cervantes, M. E. (2012). The role of sexual compulsivity, impulsivity, and experiential avoidance in internet pornography use. Psychological Record, 62(1), 3-18. https://doi.org/10.1007/BF03395783.

Willig, C. (2019). What can qualitative psychology contribute to psychological knowledge? Psychological Methods, 9141, 0-1. https://doi. org/10.1037/met0000218.

Yin, R. K. (2018). Case Study Research and Applications: Design and Methods ( $6^{\text {th }}$ Ed.). California: Sage Publications.

Young, K. (2009). Understanding online gaming addiction and treatment issues for adolescents. American Journal of Family Therapy, 37(5), 355-372. https:// doi.org/10.1080/01926180902942191.

Young, K. S. (1998). Internet addiction: The emergence of a new clinical disorder. Cyberpsychology and Behavior, 1(3), 237-244. https://doi.org/10.1089/ cpb.1998.1.237.

Young, K. S. (2008). Internet sex addiction: Risk factors, stages of development, and treatment. American Behavioral Scientist, 52(1), 21-37. https://doi. org/10.1177/0002764208321339. 